\title{
Assessment of relationship between acute ischemic stroke and heart disease - protocol of a prospective observational trial
}

\author{
Michal Kral ${ }^{\mathrm{a}}$, David Skoloudik ${ }^{\mathrm{a}}$, Daniel Sanak ${ }^{\mathrm{a}}$, Tomas Veverkaa ${ }^{\mathrm{a}}$, Andrea Bartkovaa ${ }^{\mathrm{a}}$, Tomas Dornaka ${ }^{\mathrm{a}}$, Martin Hutyrab \\ David Vindis ${ }^{\mathrm{b}}$, Jana Ulehlova' ${ }^{c}$ Ludek Slavikc, Marija Svabovad ${ }^{d}$, Veronika Kubickova ${ }^{d}$, Roman Herziga ${ }^{a}$, Petr Kanovsky ${ }^{\mathrm{a}}$
}

\begin{abstract}
Background. Stroke and acute myocardial infarction are the leading causes of death and disability in industrialized countries. Multiple interactions exist between the various forms of cardiovascular and cerebrovascular diseases, and risk factors for development of stroke and major cardiovascular events are similar. There is currently no clear link between acute coronary syndrome and stroke, although it has been repeatedly described. In addition, there are currently no clear recommendations for how to proceed in the case of signs of myocardial damage in patients with acute stroke and how to manage the next follow-up.
\end{abstract}

Methods-Design. In this prospective observational trial, 500 consecutive ischemic stroke patients admitted at the Comprehensive Stroke Center will be enrolled within $12 \mathrm{~h}$ from stroke onset. The set of examinations will consist of: 1) Acute brain computed tomography or magnetic resonance imaging 2) Laboratory tests: A) within $12 \mathrm{~h}$ from stroke onset: NT pro B-type of natriuretic peptide, pro-atrial natriuretic peptide, creatinekinase MB, troponin T (cTnT), interleukin 6, procalcitonin, high sensitive C-reactive protein and D-dimers. B) control level of cTnT after $4 \mathrm{~h}$ from admission C) nonacute laboratory samples within $60 \mathrm{~h}$ from stroke onset: glycated haemoglobine, serum lipids; 3) Electrocardiogram (ECG) on admission and $4 \mathrm{~h}$ from stroke onset; 4) Transesophageal or transthoracal echocardiography and 24-h ECGHolter within 15 days from stroke onset; 5) Neurosonological examination within $60 \mathrm{~h}$ from stroke onset; 6) Thirty patients with a positive finding of acute myocardial ischemia (ECG, CTnT) will be examined by coronary angiography (CAG); 7) Epidemiological data will be acquired.

Statistics. The epidemiological characteristics of the whole sample of patients; correlation between differences between group of cardioembolic ischemic stroke patients and group of patients with ischemic stroke of another etiology; correlation of infarction volume on DWI-MRI with the level of CTnT; correlation of the ECG findings with the level of cTnT and clinical signs; correlation of the CAG findings with level of CTnT and ECG findings will be statistically evaluated at the $5 \%$ level of statistical significance.

Conclusion. The main goal of the project is to improve identification of patients with acute coronary syndrome and with concurrent acute ischemic stroke as these patients require specific treatment and secondary prevention of ischemic events.

Trial registration. Clinicaltrials.gov NCT01541163.

Keywords: acute ischemic stroke, ischemic heart disease, acute coronary syndrome, neuromediation, brain infarction volume

Received: June 26, 2012; Accepted with revision: September 26, 2012; Available online: September 30, 2012 http://dx.doi.org/10.5507/bp.2012.094

${ }^{a}$ Comprehensive Stroke Center, Department of Neurology, University Hospital Olomouc and Faculty of Medicine and Dentistry, Palacky University Olomouc, Czech Republic

${ }^{b}$ Department of Internal Medicine I - Cardiology, University Hospital Olomouc and Faculty of Medicine and Dentistry, Palacky University Olomouc

'Department of Hemato-oncology, University Hospital Olomouc and Faculty of Medicine and Dentistry, Palacky University Olomouc ${ }^{d}$ Department of Clinical Bicohemistry, University Hospital Olomouc and Faculty of Medicine and Dentistry, Palacky University Olomouc Corresponding author:Michal Kral, e-mail:kral_michal@centrum.cz

\section{INTRODUCTION}

Stroke and acute myocardial infarction are the leading causes of death and disability in industrialized countries ${ }^{1}$. Multiple interactions exist between the various forms of cardiovascular and cerebrovascular diseases, and risk factors for the development of stroke and major cardiovascular events are similar ${ }^{2}$. After acute myocardial injury, stroke incidence is markedly increased, particularly early after the cardiac event ${ }^{3-5}$. Likewise, in patients surviving cerebrovascular diseases, other manifestations of cardiovascular disease, particularly coronary artery disease, are the main causes of long-term mortality ${ }^{6,7}$.

There is currently no clear link between acute coronary syndrome and stroke, although it has been repeatedly described $^{8-13}$. Due to the acute stroke, clinical symptoms of acute coronary syndrome may be blurred and, cause of the association between acute stroke and acute coronary syndrome has not yet been completely verified. There are two main theories: 1) myocardial damage caused by 
neuromediation during stroke brain damage and, 2) the combination of underlying ischemic heart disease and acute stroke. The latter theory is preferred.

Ischemic heart disease in the elderly may goes unnoticed because of memory impairment, absence of symptoms, and diminished patient physical activity ${ }^{14}$. Moreover, symptoms of acute coronary syndrome are often blurred because stroke is more severe, making it difficult for patients to cooperate and adequately report symptoms - due to cognitive impairment, speech disturbances, agitation, delirium and other disorders of consciousness ${ }^{15-17}$. In addition, coronary angiography (CAG) in acute stroke patients could be dangerous and there are currently no clear recommendations on how to proceed in the case of signs of myocardial damage in patients with acute stroke and how to manage the next follow-up.

\section{AIM OF THE TRIAL}

The aim of the project is to clarify the relationship between acute ischemic stroke and concomitant heart disease. The etiology of ischemic stroke will be classified according the TOAST classification ${ }^{18}$ and presence of all known risk factors will be investigated. The biochemical, imaging and clinical parameters and markers of possible coexisting acute heart disease will be investigated in the prospective study in acute ischemic stroke patients. In selected patients, analysis of the correlation between stroke volume on brain DWI-MRI scans and troponin T (cTnT) levels and correlation between cTnT levels, ECG, clinical symptoms and findings on CAG will be performed.

Analysis of acquired data will identify the patient group with concomitant heart disease, which requires the specific treatment strategy and secondary prevention.

\section{METHODS-DESIGN}

\section{Working hypothesis}

Thanks to detailed further cardiologist investigation (echocardiography, Holter ECG, CAG), it will be possible to assess the incidence of acute coronary syndrome and other heart diseases in acute stroke patients. Owing to detailed brain imaging (MRI), it will be possible to correlate acute coronary with potential neuromediation in acute stroke patients caused by direct brain damage.

Using complex cardiological examination we predict: 1) more accurate detection of patients with concomitant heart disease (cardiac rhythm disorder, valve disorders, acute coronary syndromes, cardiac thrombus and myxoma, atrial and ventricular septum defects) and 2) higher number of etiologically determined IS, which is crucial for accurate secondary prevention.

We predict significant changes in biochemical parameters (NT pro B-type of natriuretic peptide, pro-atrial natriuretic peptide, creatine kinase MB, cTnT), inflammatory markers (interleukin 6, procalcitonin, high sensitive C-reactive protein), and coagulation parameters (D-dimers) in patients with cardioembolic ischemic stroke compared to other causes of ischemic stroke.

Assessing the glomerular filtration of cystatin C, glycated haemoglobin and serum lipids and its correlation with prior medication will allow us to evaluate the longterm compensation of arterial hypertension, diabetes mellitus and dyslipidemia in ischemic stroke patients.

\section{Patients}

The enrolment of 500 consecutive ischemic stroke patients within $12 \mathrm{~h}$ from ischemic stroke onset, who will be admitted at the Comprehensive Stroke Center during the period 2009 - 2014 is planned. Inclusion and exclusion criteria are listed in Table 1.

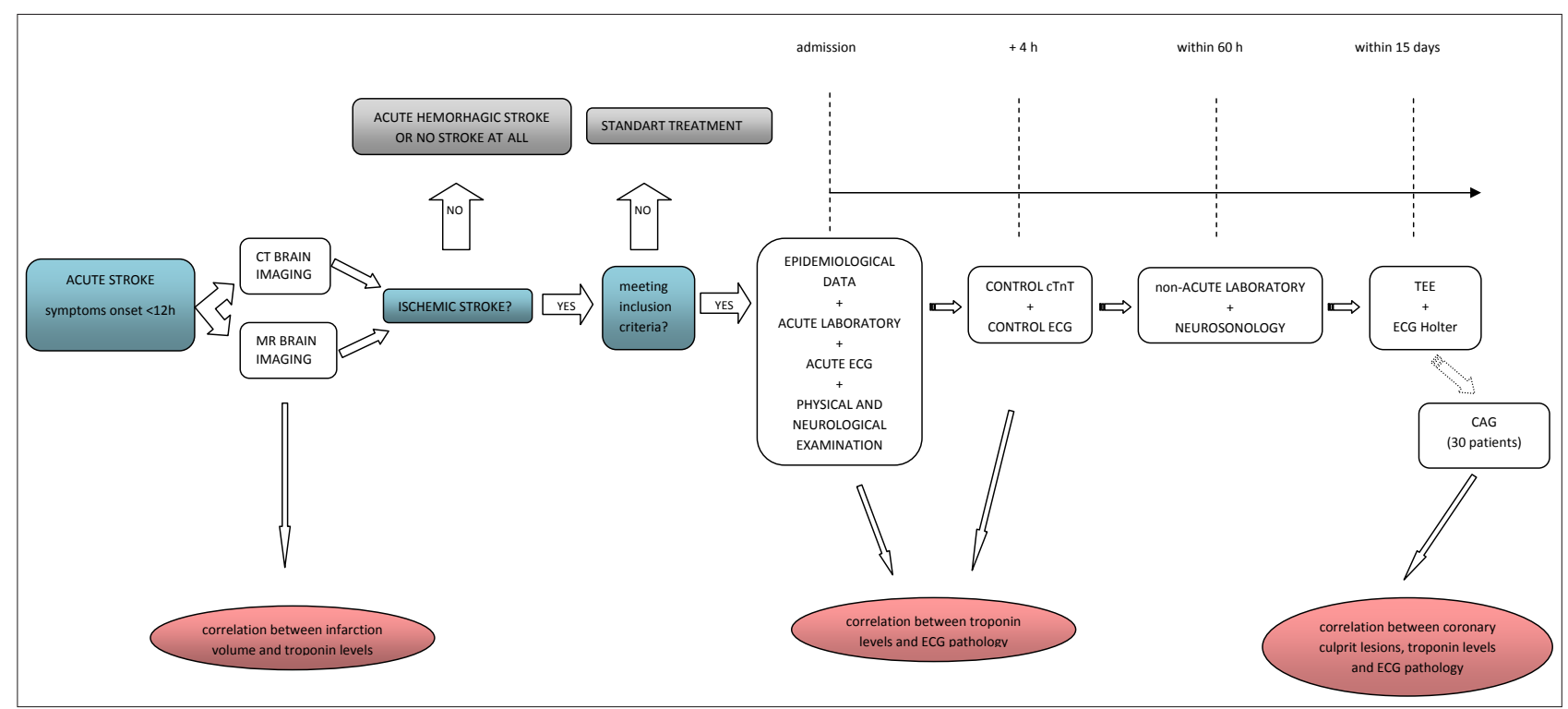

Fig. 1. Study flow chart.

Red ellipses - Outcome measures, Blue boxes - Study population, Gray boxes - Excluded population.

CAG, coronary angiography; CT, computed tomography; cTnT, troponin T; ECG, electrocardiogram; MR, magnetic resonance; TEE, transesophageal echocardiography. 
Table 1. Inclusion and exclusion criteria.

\begin{tabular}{ll}
\hline Inclusion criteria & 1. Acute ischemic stroke, confirmed by CT or MR cerebral imaging \\
& 2. Enrolment within $12 \mathrm{~h}$ after symptoms onset \\
& 3. The ability and willingness to sign the informed consent \\
\hline Exclusion criteria & $\begin{array}{l}\text { 1. Other etiology of symptoms than ischemic stroke } \\
\text { 2. Age }<18 \text { years } \\
\text { 3. Pregnancy } \\
\text { 4. Probable survival of less than } 7 \text { days }\end{array}$ \\
\hline
\end{tabular}

CT, computed tomography; MR, magnetic resonance.

\section{Diagnostics}

Flow chart of the project with planned examinations is presented in Fig. 1.

Physical and neurological examination: Physical and neurological examinations will be performed by certified investigators using the National Institute of Health Stroke Scale (NIHSS) to evaluate stroke severity and to grade neurological deficit ${ }^{19,20}$ and modified Rankin scale (mRS) to evaluate the degree of disability ${ }^{21-22}$. Patients will be scored on admission and on hospital discharge, which is typically between Day 6 and Day 10 after hospital admission.

Imaging: All patients will undergo chest X-ray examination. Whenever possible, brain imaging will be done using 1.5T MRI Siemens Symphony (Siemens AG, Erlangen, Germany) or 1.5T MRI Siemens Avanto (Siemens AG, Erlangen, Germany) instrument Statistical correlation of the infarction volume on DWI-MRI with serum cTnT level will be done in patients with acute brain MRI examination. Patients contraindicated for MRI will be examined with cerebral computed tomography using GE Light Speed VCT64 (GE Healthcare Europe, Buc, France) apparatus.

Laboratory tests: Laboratory tests will be performed in the certificated laboratories of the Department of Hematooncology and Department of Clinical Biochemistry, University Hospital Olomouc. The following tests will be performed in patients meeting the inclusion criteria (beside the standard laboratory tests performed in all acute stroke patients, i.e. tests for electrolytes, renal and liver functions parameters, blood count, basic coagulation):

A) acute laboratory markers within $12 \mathrm{~h}$ from stroke onset: NT pro B-type of natriuretic peptide, pro-atrial natriuretic peptide, creatine kinase $\mathrm{MB}$, cTnT, interleukin 6, procalcitonin, high sensitive $\mathrm{C}$-reactive protein and D-dimers,

B) control level of cTnT within $4 \mathrm{~h}$ from the collection of acute laboratory markers,

C) non-acute laboratory markers within $60 \mathrm{~h}$ from stroke onset: glycated haemoglobine, serum lipids, coagulation parameters, genetic examination. For details, and normal values of the used specific methods see (Table 2).

Electrophysiology: Electrocardiogram (ECG) will be performed on admission and $12 \mathrm{~h}$ after stroke onset. Examination of 24-h ECG Holter monitoring will be performed using Philips DigiTrak XT machine (Philips Healthcare, Best, Netherlands).

Coronary angiography: Thirty patients with a positive finding of acute myocardial ischemia (ECG, cTnT) will be examined by CAG.

Echocardiography: Transesophageal echocardiography or transthoracic echocardiography investigations will be performed using GE Ultrasound Vingmed Vivid 7 Dimension (GE Healthcare Technologies, Waukesha, WI, USA) instrument equipped with transthoracic multifrequnce matrix ultrasound probe and multiplanar probe for transesophageal examination with possibility of off-line analysis speckle tracking echocardiography. All Doppler applications include tissue doppler echocardiography, quantitative TVI analysis and echocontrast, velocity profiles, strain/strain rate profiles, analysis of amplitude, anatomic M-mode.

Neurosonology: Ultrasound examination of carotid, vertebral and cerebral arteries will be performed within $24 \mathrm{~h}$ from stroke onset using Phillips HD 11SE (Phillips, Bothel, WA, USA) apparatus.

Medical history: Epidemiological data will be collected - age, gender, nicotine and alcohol consumption, previous history of stroke or peripheral embolism, history of other vascular diseases (coronary artery disease, peripheral artery disease, carotid artery stenosis, heart failure and atrial fibrillation), history of vascular risk factors (diabetes mellitus, atrial fibrillation, hyperlipidemia, arterial hypertension, coagulopathy) and administration of appropriate treatment.

\section{Statistics}

Statistical evaluation will be performed at the Department of Medical Biophysics, Faculty of Medicine and Dentistry, Institute of Molecular and Translational Medicine, Palacký University Olomouc. The epidemiological characteristics of the whole sample of patients; correlation between differences between group of patients with cardioembolic ischemic stroke patients and group of patients with ischemic stroke of another etiology; correlation of the infarction volume on DWI-MRI with the level of cTnT; correlation of the ECG findings with the level of cTnT and cardiac clinical signs; correlation of the CAG findings with the level of cTnT and ECG findings will be statistically evaluated at $5 \%$ level of statistical significance 
Table 2. Laboratory tests.

\begin{tabular}{|c|c|c|c|}
\hline & test & method & normal values \\
\hline \multirow{21}{*}{$\begin{array}{l}\text { Coagulation } \\
\text { parameters }\end{array}$} & aPTT & $\mathrm{COAG}$ & $22-36 s$ \\
\hline & prothrombin time & COAG & $70-101 \%$ \\
\hline & fibrinogen & COAG & $1.8-4.5 \mathrm{~g} / \mathrm{L}$ \\
\hline & D-dimers & LIA & $0-0.24 \mu \mathrm{g} / \mathrm{mL}$ \\
\hline & thrombin time & COAG & $10-18 \mathrm{~s}$ \\
\hline & factor II & COAG & $80-130 \%$ \\
\hline & factor VIII & COAG & $60-140 \%$ \\
\hline & factor IX & COAG & $73-130 \%$ \\
\hline & factor XI & COAG & $77-130 \%$ \\
\hline & vWF: Ag & LIA & $61-158 \%$ \\
\hline & vWF: activity & LIA & $40-163 \%$ \\
\hline & protein $\mathrm{C}$ & CHROM & $72-146 \%$ \\
\hline & free protein $S$ & LIA & F: $53-109 \% ; M: 65-129 \%$ \\
\hline & APC resistance & COAG & negative $(\mathrm{R}=1.95$ to 9.00$)$; positive $(\mathrm{R}<1.95)$ \\
\hline & antitrombin & CHROM & $75-125 \%$ \\
\hline & plasminogen & CHROM & $89-112 \%$ \\
\hline & $\alpha$-2-antiplasmin & CHROM & $75-120 \%$ \\
\hline & $\mathrm{tPA}$ & ELISA & $2.0-8.0 \mathrm{ng} / \mathrm{mL}$ \\
\hline & PAI-1 & ELISA & $7-43 \mathrm{ng} / \mathrm{mL}$ \\
\hline & lupus anticoagulant & dRVVT & negative $(\mathrm{R}<1.20)$; positive $(\mathrm{R} \geq 1.20)$ \\
\hline & TAFI & ELISA & $83.5-132.5 \%$ \\
\hline \multirow{17}{*}{$\begin{array}{l}\text { Clinical } \\
\text { biochemistry }\end{array}$} & cholesterol & ECT & $2.9-5.0 \mathrm{mmol} / \mathrm{L}$ \\
\hline & triacylglycerols & $\mathrm{ECT}$ & $0.45-1.7 \mathrm{mmol} / \mathrm{L}$ \\
\hline & HDL-cholesterol & ECT, DHM & $\mathrm{F}: 1.2-2.7 \mathrm{mmol} / \mathrm{L} ; \mathrm{M}: 1.0-2.1 \mathrm{mmol} / \mathrm{L}$ \\
\hline & LDL-cholesterol & IT & $1.2-3.0 \mathrm{mmol} / \mathrm{L}$ \\
\hline & Apolipoprotein A1 & IT & $\mathrm{F}: 1.1-1.9 \mathrm{~g} / \mathrm{L} ; \mathrm{M}: 1.0-1.7 \mathrm{~g} / \mathrm{L}$ \\
\hline & Apolipoprotein B & IT & $0.5-1.2 \mathrm{~g} / \mathrm{L}$ \\
\hline & Lipoprotein (a) & IT & $0.0-0.3 \mathrm{~g} / \mathrm{L}$ \\
\hline & C-reactive protein & IT & $0.0-5.0 \mathrm{mg} / \mathrm{L}$ \\
\hline & Interleukin-6 & ECLIA & $1.5-7.0 \mathrm{mg} / \mathrm{L}$ \\
\hline & procalcitonin & ECLIA & $0.0-0.5 \mu \mathrm{g} / \mathrm{L}$ \\
\hline & troponin $\mathrm{T}$ & ECLIA & $0.0-0.014 \mu \mathrm{g} / \mathrm{L}$ \\
\hline & NT-pro BNP & ECLIA & $0,1-125 \mu \mathrm{g} / \mathrm{L}$ \\
\hline & CK-MB mass & ECLIA & $\mathrm{F}: 1.0-2.88 \mu \mathrm{g} / \mathrm{L} ; \mathrm{M}: 1.35-4.94 \mu \mathrm{g} / \mathrm{L}$ \\
\hline & cystatin $\mathrm{C}$ & IT & $\begin{array}{r}1 \text { - } 50 \text { years: } 0.55-1.15 \mathrm{mg} / \mathrm{L} \\
>50 \text { years: } 0.63-1.44 \mathrm{mg} / \mathrm{L}\end{array}$ \\
\hline & CDT & HPLC & $0.0-1.9 \%$ \\
\hline & pro-ANP & TRACE & $85.2 \mathrm{pmol} / \mathrm{L}$ for $97.5 \%$ percentile \\
\hline & glycated haemoglobin (HbA1c) & HPLC & $0.0-43.0 \mathrm{mmol} / \mathrm{mol}$ \\
\hline
\end{tabular}

Genetic examination

factor V Leiden, FIIG20210A polymorphism, MTHFR polymorphism, PAI polymorphism

Ag, antigen; ANP, Atrial Natriuretic Peptide; APC, Activated Protein C; aPTT, activated Partial Thromboplastin Time; CDT, Carbohydrate Deficient Transferrin; CHROM, Chromogenic Method; CK-MB, Creatine Kinase MB; COAG, Coagulation Method; DHM, Direct Homogeneous Method; dRVVT, dilute Russell's Viper Venom Time; ECLIA, Electrochemiluminescence Immunoassay; ECT, Enzymatic Colorimetric Test; ELISA, Enzyme-Linked Immunosorbent Assay; HDL, High-Density Lipoprotein; HPLC, High-Performance Liquid Chromatography; IT, Immunoturbidimetric Test; LDL, Low-Density Lipoprotein; LIA, Latex Immuno-Assay; MTHFR, Methylenetetrahydrofolate Reductase; NT-pro BNP, N-Terminal pro Brain Natriuretic Peptide; PAI-1, Plasminogen Activator Inhibitor-1; TAFI, Thrombin Activatable Fibrinolysis Inhibitor; tPA, tissue Plasminogen Activator; TRACE, Time Resolved Amplified Cryptate Emission; vWF, von Willebrand Factor. 
using the Mann-Whitney U test, Student t-test, $\chi 2$-test, ANOVA and regression analysis.

\section{Ethics}

The entire study and was approved by the Local Ethics Committees of University Hospital Olomouc in December 2009 and will be conducted in accordance with the Helsinki Declaration of 1975 (as revised in 2004 and 2008). Trial registration was performed in February 2012 (clinicaltrials.gov NCT01541163).

\section{DISCUSSION}

There are a number of challenges to diagnosing acute coronary syndrome in patients with acute ischemic stroke: due to impaired consciousness, confusion, speech disturbances, modification of clinical signs and laboratory factors. Moreover, no specific guidelines exist for the management of patients with coincidence of acute ischemic stroke and acute coronary syndrome.

A similar theme of the association between acute ischemic stroke and heart disease is under investigation in the TRELAS (TRoponin ELevation in Acute ischemic Stroke) trial, in which the primary objective is to assess the frequency and the underlying pathomechanism of cTnT elevation in acute ischemic stroke patients $^{23}$. TRELAS is a prospective, observational, single center, matched-pair controlled trial conducted by the Center for Stroke Research Berlin and the Department of Cardiology at the Campus Benjamin Franklin of the Charité University Hospital, Berlin, Germany. The study plans to include 29 consecutive patients with imagingconfirmed stroke admitted within $72 \mathrm{~h}$ after symptoms onset to the Department of Neurology with cTnT elevation (i.e. $\geq 0.05 \mu \mathrm{g} / \mathrm{L}$ ) and normal serum creatinine $(\leq 1.2 \mathrm{mg} / \mathrm{dL})$, in whom CAG will be carried out within the next $72 \mathrm{~h}$. The control group should consist of 29 ageand gender-matched patients with non-ST-elevation- ACS (NSTE-ACS), thus showing elevated cTnT levels above $0.05 \mu \mathrm{g} / \mathrm{L}$. The control group allows comparison with regard to frequency of culprit lesions and left ventricular (LV) dysfunction.

The primary hypothesis of TRELAS is that cTnT elevation in acute stroke patients is generally not caused by coincidental myocardial infarction. Thus, TRELAS authors predict angiographic culprit lesions to occur less frequently in patients with acute stroke and elevated cTnT than in patients with NSTE-ACS. Further, they hypothesize that strokes affecting the insular cortex can be found more often in patients with increased cTnT than in those with normal cTnT. A further secondary hypothesis is that LV global cardiac dysfunction occurs more frequently in stroke patients with increased cTnT than in patients with NSTE-ACS. Therefore, the findings of the left ventriculography will serve as an outcome measure.

\section{CONCLUSION}

The main goal of the project is to improve identification of patients with acute coronary syndrome and with concurrent acute ischemic stroke as these patients require specific treatment and secondary prevention of ischemic events.

\section{ABBREVIATIONS}

CAG, coronary angiography; cTnT, troponin T; DWIMRI, diffusion-weighted imaging - magnetic resonance imaging; ECG, electrocardiogram; MRI, magnetic resonance imaging; TOAST classification, Trial of Org 10172 in Acute Stroke Treatment clasiffication; TVI, Tissue Velocity Imaging.

\section{ACKNOWLEDGMENTS}

The project has received funding from the Internal Grant Agency of Ministry of Health of the Czech Republic via the grant no. NT/11046-6/2010.

\section{CONFLICT OF INTEREST STATEMENT}

Author's conflict of interest disclosure: The authors stated that there are no conflicts of interest regarding the publication of this article.

\section{REFERENCES}

1. Thom T, Haase N, Rosamond W, Howard VJ, Rumsfeld J, Manolio T, Zheng ZJ, Flegal K, O'Donnell C, Kittner S, Lloyd-Jones D, Goff DC Jr, Hong Y, Adams R, Friday G, Furie K, Gorelick P, Kissela B, Marler J, Meigs J, Roger V, Sidney S, Sorlie P, Steinberger J, Wasserthiel-Smoller $\mathrm{S}$, Wilson M, Wolf P; American Heart Association Statistics Committee and Stroke Statistics Subcommittee. Heart disease and stroke statistics-2006 update: a report from the American Heart Association Statistics Committee and Stroke Statistics Subcommittee. Circulation 2006;113:e85-e151.

2. Pearson TA, Blair SN, Daniels SR, Eckel RH, Fair JM, Fortmann SP, Franklin BA, Goldstein LB, Greenland P, Grundy SM, Hong Y, Miller $\mathrm{NH}$, Lauer RM, Ockene IS, Sacco RL, Sallis JF Jr, Smith SC Jr, Stone NJ, Taubert KA. AHA guidelines for primary prevention of cardiovascular disease and stroke: 2002 update: consensus panel guide to comprehensive risk reduction for adult patients without coronary or other atherosclerotic vascular diseases. American Heart Association Science Advisory and Coordinating Committee. Circulation 2002;106:388-91.

3. Fuster V, Halperin JL. Left ventricular thrombi and cerebral embolism. N Engl J Med 1989;320:392-4.

4. Witt BJ, Brown RD Jr, Jacobsen SJ, Weston SA, Yawn BP, Roger VL. A community-based study of stroke incidence after myocardial infarction. Ann Intern Med 2005;143:785-92.

5. Mooe T, Olofsson BO, Stegmayr B, Eriksson P. Ischemic stroke. Impact of a recent myocardial infarction. Stroke 1999;30:997-1001.

6. Touze E, Varenne O, Chatellier G, Peyrard S, Rothwell PM, Mas JL. Risk of myocardial infarction and vascular death after transient ischemic attack and ischemic stroke: a systematic review and meta-analysis. Stroke 2005;36:2748-55.

7. Truelsen T, Gronbaek M, Schnohr P, Boysen G. Stroke case fatality in Denmark from 1977 to 1992: the Copenhagen City Heart Study. Neuroepidemiology 2002;21:22-7. 
8. Goldstein DS. The electrocardiogram in stroke: relationship to pathophysiological type and comparison with prior tracings. Stroke 1979;10:253-9.

9. Lindgren A, Wohlfart B, Pahlm O, Johansson BB. Electrocardiographic changes in stroke patients without primary heart disease. Clin Physiol 1994;14:223-31.

10. Kolin A, Norris JW. Myocardial damage from acute cerebral lesions. Stroke 1984;15:990-3.

11. Dimant J, Grob D. Electrocardiographic changes and myocardial damage in patients with acute cerebrovascular accidents. Stroke 1977;8:448-55.

12. Myers MG, Norris JW, Hachinski VC, Weingert ME, Sole MJ. Cardiac sequelae of acute stroke. Stroke 1982;13:838-42.

13. Norris JW, Hachinski VC, Myers MG, Callow J, Wong T, Moore RW. Serum cardiac enzymes in stroke. Stroke 1979;10:548-53.

14. Sheifer SE, Gersh BJ, Yanez ND III, Ades PA, Burke GL, Manolio TA Prevalence, predisposing factors, and prognosis of clinically unrecognized myocardial infarction in the elderly. J Am Coll Cardiol 2000;35:119-26.

15. Chalela JA, Ezzeddine MA, Davis L, Warach S. Myocardial injury in acute stroke: a troponin I study. Neurocrit Care 2004;1:343-6.

16. Christensen $\mathrm{H}$, Johannesen $\mathrm{HH}$, Christensen AF, Bendtzen K, Boysen $\mathrm{G}$. Serum cardiac troponin I in acute stroke is related to serum cortisol and TNF-alpha. Cerebrovasc Dis 2004;18:194-9.
17. Trooyen M, Indredavik B, Rossvoll O, Slordahl SA. Myocardial injury in acute stroke assessed by troponin I. Tidsskr Nor Laegeforen 2001; 121:421-5.

18. Adams HP, Bendixen BH, Kappelle LJ, Biller J, Love BB, Gordon $\mathrm{DL}$, Marsh EE. Classification of subtype of acute ischemic stroke. Definitions for use in a multicenter clinical trial. TOAST. Trial of Org 10172 in Acute Stroke Treatment. Stroke 1993;24:35-41.

19. Brott T, Adams HP, Olinger CP, Marler JR, Barsan WG, Biller J, Spilker J, Holleran R, Eberle R, Hertzberg V. Measurements of acute cerebral infarction: a clinical examination scale. Stroke 1989;20:864-70.

20. Goldstein LB, Bertels C, Davis JN. Interrater reliability of the NIH stroke scale. Arch Neurol 1989; 46:660-2.

21. van Swieten JC, Koudstaal PJ, Visser MC, Schouten HJ, van Gijn J. Interobserver agreement for the assessment of handicap in stroke patients. Stroke 1988;19:604-7.

22. Banks JL, Marotta CA. Outcomes validity and reliability of the modified Rankin scale: implications for stroke clinical trials: a literature review and synthesis. Stroke 2007;38:1091-6.

23. Scheitz JF, Mochmann HC, Nolte CH, Haeusler KG, Audebert HJ, Heuschmann PU, Laufs U, Witzenbichler B, Schultheiss HP, Endres M. Troponin elevation in acute ischemic stroke (TRELAS) - protocol of a prospective observational trial. BMC Neurol [serial on the internet]. 2011 Aug;11:98. Available from: http://www.biomedcentral. com/1471-2377/11/98 